\author{
PAUL SUTTON
}

\title{
CARIBBEAN DEVELOPMENT: AN OVERVIEW
}

In September 1999, the University of the West Indies (UWI), in cooperation with the CARICOM secretariat and the Caribbean Development Bank, held a major conference on the theme of "The Caribbean in the $21^{\text {st }}$ Century." The discussions ranged widely over the history, geography, economy, society, politics, culture, and environment of the region and provided a mix of analytical insight and practical proposal. Those addressing the conference included three Caribbean prime ministers, senior officials from regional organizations, leading Caribbean academics, and policy advisors in nongovernmental organizations and the private sector. Among the conclusions drawn from the proceedings by the organizers of the conference, Kenneth Hall and Denis Benn (2000: xiii-xxix), were "an urgent need to revisit conventional economic policies and to adopt creative strategies capable of generating higher levels of growth with equity," "the need to re-orient existing governance structures by promoting effective constitutional change and suitable public sector reforms," "the demand for increased social equity as a basis for social stability," "the adoption of suitable policies designed to promote art and culture as an integral aspect of the overall development of the region," and the need for the Caribbean to think differently about its international relations given the diminishing "geopolitical and geo-strategic significance of the region" which had "reduced its bargaining position in both the hemispheric and wider global system."

These are important observations which should be borne in mind in any contemporary discussion of development in the Caribbean. The region is currently facing a serious development challenge. It is by no means certain that the region, or at least some of the more vulnerable parts of it such as Haiti, Guyana, and the Windward Islands, can adapt to survive. The publication of two reports in 2005 setting out the range and depth of problems facing the region is therefore both welcome and timely. The first, by the World Bank enti-

1. This is a revised and expanded version of a presentation originally given to the meeting of the Development Policy and Review Network on "Caribbean Development in the 21 st Century," KITLV, Leiden, December 12, 2005.

New West Indian Guide / Nieuwe West-Indische Gids vol. 80 no. $1 \& 2$ (2006):45-62 
tled $A$ Time to Choose: Caribbean Development in the $21^{\text {st }}$ Century ${ }^{2}$ takes up the same challenge as the UWI conference. It provides a massive and detailed empirical account of the economic challenges facing the region and sets out policies to deal with them. Given the importance of the World Bank in setting the development discourse and mobilizing resources from the international community, it is bound to be influential. For that reason alone it ought to be read and discussed by anyone with a serious interest in Caribbean development. At the same time, it is deeply flawed, not least because it overlooks precisely what the UWI conference did so much to assert, the unique specificity of the region and the importance of those who live and work in the Caribbean in understanding its true character and contributing to its development.

The second is the United Nations Economic Commission for Latin America and the Caribbean (ECLAC) report, The Millennium Development Goals: A Latin American and Caribbean Perspective. ${ }^{3}$ This is a contribution to the much wider development agenda approved by the United Nations in 2000. It set eight millennium development goals to be achieved by the year 2015 on the basis of the global situation during the 1990s. The Millennium Development Goals report provides a counterpoint to the World Bank report by emphasizing a broader development agenda. It also provides a commentary on the major social problems facing the region. In comparison to those in some other parts of the developing world, such as south Asia and sub-Saharan Africa, the problems in the Caribbean seem manageable and the prospect of meeting at least some of the development goals, quite good. ${ }^{4}$ Nevertheless, the ECLAC report identifies real poverty in the Caribbean, which is so often masked by the description of most of the countries as "middle-income" and not needing international assistance and support. This view is misplaced, particularly in regard to the smaller countries of the region, many of which remain crucially dependent on external support for their development and prosperity.

Together these reports provide a "snapshot" of the development problematic in the region. They provide some useful "new thinking" and a wealth of empirical material. It is, however, the contention of this article that these reports need to be set in context. The main argument presented in this "overview" of development is that development policy without a deep understanding of what

2. Report No. 31.725-LAC. Available online through http://www.wds.worldbank.org.

3. Coordinated by José Luis Machinea, Alicia Bárcena \& Arturo León, 2005. Available online at http://www.undp.org/rblac/mdg/regional/interagency.pdf.

4. See the Mauritius Strategy <http://www.sidsnet.org/docshare/other/20050222171 050_Mauritius_Strategy_latest_version.pdf $>$ and the Mauritius Declaration $<\mathrm{http}: / / \mathrm{www}$. sidsnet.org/docshare/other/20050201154324_Mauritius_Declaration.pdf $>$ from the International Meeting to Review the Implementation of the Programme of Action for the Sustainable Development of Small Island Developing States held in Port Louis, Mauritius, January 2005. 
makes the Caribbean different will be development policy that ultimately will not deliver the level and type of development that meets the region's needs.

\section{A MATtER OF DEFinition}

Development is generally recognized as a complex multifaceted process of economic, social, political, environmental, and cultural change resulting in increases in the well-being of people and extending their rights and choices in the present without compromising the abilities of future generations to enjoy these benefits. In the Caribbean the economic, social, and political elements of development have held center stage in the last fifty years. Typically they have been (and are) represented in the form of rising incomes (greater Gross Domestic Product per capita), social progress (improved welfare through education and health programs and gender equality) and political freedoms (independence, administrative efficiency, and democracy). In the last fifteen years environmental issues have slowly risen on the development agenda as well as, more recently, cultural issues such as artistic expression and various forms of identity.

Any exploration of development in the region is therefore very wide. The focus of this article is on the traditional agenda - economic, social, and political development, in that order. This is not because these aspects are in any sense "superior" to other forms of development (although the economic dimension remains dominant within the development discourse and within the Caribbean), but because it permits the long view - it enables one to look back at development policy to situate where the theory and practice of development is now and where it may go in the future. In turn this may mean looking again at what constitutes development in the region.

In order to proceed, however, there are two issues that must be addressed. The first is a familiar one: the definition of the Caribbean. In presenting statistics and some of the current arguments on development this article cites extensively from the two reports released in 2005. The World Bank report focuses only on the independent Caribbean countries, so excluding the dependent and overseas territories of France, the Netherlands, the United Kingdom, and the United States of America. It also continues to exclude Cuba. The ECLAC report has a separate section for the Caribbean including the Caribbean Community (CARICOM) countries and all the dependent and overseas territories, but excludes from it Cuba, the Dominican Republic, and Haiti, which it treats within the Latin American dimension of the report. The definition of the region would thus still appear to depend on where you sit, and this necessarily makes comparability between countries difficult to determine (statistically and otherwise, for example, in terms of generalization and policy recommendation).

The other is Cuba, and more marginally, Haiti. It is difficult to include 
Cuba in any study of development without recognizing its unique development model, which has implications for all the dimensions of development identified earlier. The analysis within the paper therefore does not generally hold for Cuba. The same also applies to Haiti to some degree. Its pattern of underdevelopment (if not its strategy and aspiration for development) mean that caution is needed in applying them to Haiti. To exclude from consideration some half of the population of the Caribbean is unsatisfactory but regrettably inevitable if one is to make better sense of the remainder. At the same time it can also serve as a reminder of the difficulties and of the failure of development in Haiti; and in Cuba of the existence of an alternative to the dominant capitalist development discourse and practice in the region. These are matters that are considered again toward the end of the article.

\section{ECONOMIC DEVELOPMENT}

The World Bank report points to high but declining economic growth figures for the region. In the period 1961-2002 the average per capita growth for a median Caribbean country was 2.8 percent, higher than Latin America and broadly comparable to developed (OECD) countries but lower than east Asia. In the 1990s it was only 1.9 percent, and in a scenario the World Bank presents under the title of "business as usual," that is, no change to existing patterns and policies, it projects a growth rate of only 2.2 percent per capita per year to 2010, which means a slow decline. Faced with this gloomy future the World Bank argues that for the region it is A Time to Choose to break with the past and set out in new directions.

The future it sees for the region is one in which services dominate the economy, which is already the case in many countries. The contribution of agriculture and industry to GDP has steadily fallen, with the service sector being the main contributor to growth. Services accounted for some 62 percent of GDP in the 1990s (50 percent in the 1960s) - much higher than the average (45 percent) for developing countries. Tourism is a major contributor accounting for 18 percent of total GDP and 34 percent of total employment. The Caribbean has around half the world's cruise market (fifteen million passengers annually) but the more lucrative "stopover" business (approximately the same number of visitors but accounting for more than 90 percent of total visitor expenditure) is facing difficulties from a "maturing" product at home (an established industry with a focus on beach resorts) and competition overseas, resulting in at best a static share of a growing global market. To combat this the Caribbean will need to reinvigorate its tourist industry through the development of niche products such as eco-tourism and up-market tourism.

By contrast, the World Bank sees no future in agriculture for export and only a limited future in industry. In general agriculture is marked by low pro- 
ductivity and a lack of competitiveness. It is kept alive artificially, it argues, by various preferential schemes which are seen as increasingly unsustainable. Witness here the recent reform of the sugar regime in the European Union, which has dealt a possibly mortal blow to sugar production for export in several Caribbean countries, and the impending reform of the banana regime from 2006 that will do the same for bananas. The future of agriculture for export is thus limited again to the development of niche products such as organic bananas or speciality fruit and vegetables, or products which can be agriculturally processed in the region for export to the Caribbean diaspora and speciality food markets.

Industry's share in GDP had dropped to 25 percent in the 1990s (38 percent in the 1960s). The much discussed apparel/clothing markets which benefited under special arrangements, especially with the United States, have not developed as anticipated, and the World Bank sees little real future for such enterprises outside of the Dominican Republic (and less so Haiti and Jamaica). Mineral extraction remains important in a few places, but only in Trinidad and Tobago is there any realistic chance for large-scale industry to develop (based on natural gas and its by-products) and to hold its own in a global, competitive market. Regrettably this development is not discussed in the report as neither is the potential for any industrial development at all. Given the importance once attached to industrialization in the region, this is a curious omission, implying that the region made a serious mistake in its development strategy in the past.

The Caribbean in most instances therefore has no choice other than to move into services in an even bigger way. The question is, "which ones?" The World Bank identifies the following: information and communication technology (ICT)-enabled products and services, offshore education, health services, and niche tourism. The effective use of ICT is seen as an essential ingredient in attaining competitiveness in both services and niche manufacturing sectors in the region. It can offset problems associated with small size and distance from markets while at the same time projecting the region abroad. Government support (nationally and regionally) would be needed to create a more competitive telecommunications sector (internet costs are currently too high) and provide services for small firms. The offshore education recommendation follows the successful establishment in the region of twenty-three offshore medical schools whose graduates together account for some 70 percent of the international medical graduates entering the United States. The need for medical schools is expected to grow as demand for medical practitioners exceeds the supply from North American medical schools, and tuition and associated costs in the Caribbean remain significantly below those in the United States. Government support is needed for accreditation and to encourage foreign direct investment in the higher education sector. Linked to the import of foreign-educated medical staff is the globalization of health services. Cuba was a leader in this field, although the model offered in the report is essentially private-sector driven and 
seeks to capitalize on the advantages of proximity to the North American market, climate, an established tourism industry, well-trained health practitioners, and established health and medical services. The Caribbean could offer health and wellness spas and in some cases medical treatment and rehabilitation. Government support would be needed for regulations covering health insurance and the provision of professional services, as well as to facilitate synergies between the tourism and offshore medical sectors. Lastly, the report proposes the reinvigoration of the tourism product in the region. The Caribbean is the most tourism intensive region in the world, but its product has failed to evolve to meet new demands. Consequently, the report argues for new approaches and innovative thinking directed toward the creation and capture of niche markets (e.g., adventure and nature-based tourism) and the promotion of tourism to cater for the very rich. Developing tourism in these directions requires a more comprehensive approach than in the past, with government activity aimed at improving the "destination product" by providing a better infrastructure for tourism (roads, water, sanitation, hotel training, etc.) and nurturing the environment, rather than supporting specific tourism projects financially. There is also a stronger need to focus on the "stopover" element and on the small tourism enterprise sector (e.g., small hotels).

These proposals, with the exception of those for ICT (and even there in part), are extensions of the familiar pattern of "offshore" Caribbean development. They are small and specialized like the offshore financial centers. Generally they do not do much for local employment although they can, in certain circumstances, boost the local economy: for example, in Dominica the medical school is estimated to contribute 8.3 percent to GDP. "Offshore development" therefore provides some opportunities, but does not overcome the vulnerabilities that many small countries face in the global system, and all proposals of this nature are based on the continuation of a buoyant overseas demand. They thus continue dependence and are hostage to developments elsewhere. The recent example of attempts at regulation of the offshore financial centres (OFCs) by the OECD illustrates the perils. In the Caribbean eighteen states and territories had established OFCs, with some of them offering a substantial array of services. For example, the Cayman Islands are among the largest OFCs in the world. The OECD, through its "harmful tax competition initiative," sought to impose, without consultation with the Caribbean OFCs, controls on their activities that would have seriously affected their attractiveness as OFCs, and hence their ability to do business. In this instance a vigorous campaign was mounted by the OFCs (with the support of powerful interest lobbies in the United States and elsewhere) and the proposals were modified and then shelved (Sanders 2002, Woodward 2004). However, the issue has not fully gone away. The European Union, for example, is committed to a Savings Tax Directive, which seeks to impose "fiscal transparency" on OFCs, so removing some of their comparative advantage (the maintenance of secre- 
cy) in the provision of financial services. There is therefore no guarantee that attempts to close down OFCs will not occur again in the future, particularly if the effects of globalization on OECD countries are judged as too harmful, or the U.S. "war on terror" demands even greater financial surveillance.

The sectors chosen by the World Bank also depend on the local availability of well-trained human resources. This is a dimension of future Caribbean development that does need to be fully explored. The report identifies unemployment as "one of the most challenging economic problems facing the Caribbean," 5 with variable but still persistent high levels of unemployment (and underemployment in rural areas) and the worrying indications that employment growth slowed in the 1990s. Those aged 15-24 account for 40-56 percent of the total unemployed, with the burden falling most on poorly educated females. This leads, among other things, the report argues, to high and growing levels of alienation, addiction, and crime. In these circumstances there is a desperate need to improve opportunity.

Developing and improving education and skills is one obvious way of tackling this problem. Whereas access to education in the region remains better than in many parts of the developing world, the Caribbean has fallen in rankings that measure years of schooling (from 47 out of 92 countries in 1970 to 52 in 2000). There is a problem of school completion rates, and the numbers in tertiary education, at 15 percent in 2000, remain below the Latin American average of 26 percent. These numbers obviously matter if the "offshore" strategy is to capitalize on "knowledge-based activity." Without appropriate education and then training it is difficult to see how this strategy can work. To realize these education goals the report advocates significant educational reforms and a greater involvement of the market. In tertiary education, for example, increased private financing, including higher fees and student loans, are proposed as a means to expand education at this level. Tertiary institutions are also urged to improve their services to the private sector through their involvement in curriculum development. The report also favors a greater role for regional agencies and the establishment of publicprivate partnerships in delivering training programmes.

The problem with this approach, as the report acknowledges, is that it can lead to "brain drain." This is nothing new, but its scale is rarely appreciated and the outmigration of educated workers is not fully explored in the report. A recent study by Mishra for the IMF reports that 12 percent of the labor force from the Caribbean emigrated to OECD member countries in 1965-2000, with rates rising to 70 percent of those who had completed tertiary education and 89 percent in the case of Guyana. ${ }^{6}$ New ways will clearly need to

5. A Time to Choose, paragraph 6.28.

6. Prachi Mishra, "Emigration and Brain Drain: Evidence from the Caribbean," IMF Working Paper No. 06/25, 2006. 
be found to ensure that the Caribbean does not "subsidize" the development of developed countries through such "brain drain" or that it receives some return for it. In the meantime, the World Bank argues that the diaspora can be better harnessed for development. Estimates suggest that there are some three million Caribbean emigrants in the United States (including more than one million from Cuba), 300,000 in Canada, and around one million in the EU. The Caribbean has seen a tenfold increase in remittances from US\$ 400 million per year in the early 1990 s to US\$ 4 billion in 2002, making the region (measured as a percentage of GDP) the largest recipient of remittances in the world. In the period from 1998-2003 remittances represented an average of 6 percent of regional GDP (and the figure could be much higher since the IMF study reports remittances as constituting 13 percent of the region's GDP in 2002). Remittances thus exceed foreign direct investment flows and overseas development assistance (ODA) combined, both of which have declined in recent years. Yet as sizeable (and as important) as remittances are, the conclusion by Mishra is that "the total losses due to skilled migration ... outweigh the recorded remittance for the Caribbean region on average, and for almost all the individual Caribbean countries," "7 suggesting that remittances are at best only partial recompense for the loss of development potential that such high-level and high-education emigration entails.

Lastly, there is a problem of mounting and increasingly unsustainable debt. High debt levels have placed seven Caribbean countries amongst the ten most indebted in the world and fourteen among the top thirty. This is generating a significant problem for public finances with the almost inevitable concomitant of a cutback in the provision of government spending and the associated reduction of public services. The smaller countries of the eastern Caribbean were among the fastest growing in the region, but as debt doubled in the 1990s, their rates of growth slowed considerably, with Dominica recently experiencing a debt crisis. In other countries, such as Jamaica and Guyana, debt has long been an issue, but only Guyana has received any respite under the HIPC initiative. The high levels of debt represent a serious diversion of government revenues from development projects and can act as a deterrent to private investment. The debt problem is not well known outside (or even inside) the region and deserves greater consideration.

\section{SOCIAL DEVELOPMENT}

The ECLAC Report seeks to put social objectives at the center of development strategy. It provides detailed commentary on a number of the millennium development goals, although insufficient data does not allow it to pro-

7. Mishra, "Emigration and Brain Drain," 2006. 
vide in-depth coverage of all the indicators for specific targets, particularly where the Caribbean is concerned. The report also argues that the extreme heterogeneity of the Latin American and Caribbean region (LAC) make generalization difficult, with frequent exceptions to be noted.

The problem of heterogeneity is well illustrated by the first goal: to eradicate extreme poverty and hunger. While LAC is making some progress to meeting the target of halving the number of people whose income is less than US\$ 1 a day, countries with low levels of human development (Haiti) will not do so without very high (and recently unprecedented) economic growth rates. In the Caribbean a more realistic benchmark poverty figure is US\$ 2 a day. On this measure progress has been made, but some countries with the lowest per capita incomes (Guyana and Suriname) will need to make greater efforts, mobilizing international as well as domestic funding. In relation to other developing regions LAC has made some modest progress but lags behind Asia.

In respect of the second goal: achieve universal primary education, LAC will not meet the target in spite of high primary enrollment rates. In the Caribbean these are at 95 percent, but there are also significant dropout rates, especially for boys. The high dropout rate obviously has enormous implications for development policies based on skilled human resources. The advantage LAC possesses on this goal (it has the highest enrolment rates in the developing world) is thus less than may generally be thought.

Goal 3 is to promote gender equality and empower women. In terms of eliminating gender disparity in primary education the entire region is on target. However, significant gaps exist in income earned by women. This is at its most marked among those with higher levels of education. There is no data on the Caribbean, but it is well known that in parts of the region, for example students enrolled at the University of the West Indies, women significantly outnumber men. As such, and even as the "world of work" is changing, existing patterns of discrimination persist and women are disadvantaged. They are, for example, still a minority in legislatures and in public life in the Caribbean.

Goal 4 is to reduce child mortality. All Caribbean countries (except Haiti) are on target to reduce child mortality rates to one-third of their 1990 levels, although some Caribbean countries (Belize, Guyana, St. Vincent, and Suriname) have made slower progress than expected. Once again, LAC as a group is more favorably placed than most other developing countries to reach this goal.

Goal 5 is to improve maternal health. While LAC has a lower maternal mortality ratio than other developing regions, it is unlikely to reach the target of reducing maternal mortality rates by three-quarters, owing to slow or no progress. Although there are some difficulties in obtaining data the evidence is that the Caribbean has a significantly higher maternal mortality rate (113 per 100,000) than the LAC average (87) with the highest rates in Guyana 
(133) and Suriname (153). The reasons for this clearly need investigation since they are probably linked to more than poverty.

Goal 6: combat HIV/AIDS, malaria, and other diseases. The Caribbean has the second-highest rate of HIV/AIDS in the world. Haiti is worst affected (5.6 percent) followed by four others with rates over 2 percent (Trinidad and Tobago, Bahamas, Guyana, and Belize). The main mode of transmission is sexual contact between men, although inevitably more women are becoming infected. The problem here, of course, is that the incidence of HIV/AIDS bears disproportionately on the most productive age group (20-45). Malaria is also a problem in French Guiana, Guyana, and Suriname.

Goal 7: ensure environmental sustainability. The report is very pessimistic about LAC meeting its targets in this area since the indicators show considerable environmental degradation in both built and natural environments. It points to the loss of biodiversity and of forests, air pollution, and the growth of slums. In Haiti some 90 percent of the urban population lives in slums, with figures above the regional average (31.9 percent) for Anguilla, the Dominican Republic, Jamaica, and Trinidad and Tobago. It also points to the need to include environmental considerations more fully into development programs and policies. The Caribbean has made some moves in this direction, and since many of them are small island developing states (SIDS) they have been included in the Barbados Programme of Action and its follow-up in Mauritius in January 2005. ${ }^{8}$ However, the Mauritius conference pointed to many weaknesses in environmental policies among both SIDS and the donor community, which had failed to support them as much as anticipated. On a more positive note, most Caribbean countries are on target in realizing a supply of clean drinking water and improving sanitation.

Goal 8: develop a global partnership for development. This covers access to markets in developed countries, debt, ODA, youth employment, and the provision of essential drugs and ICT. In most of these areas, as already noted in part, progress has been slow. In respect of trade, the Caribbean has complained of being marginalized in the current Doha Round. The region points to difficulties in getting their proposals for special and differential treatment for small and vulnerable economies on the agenda, and the devastating impact on them of the changes in the sugar and banana regimes. Guyana, for example, has pointed out that while it got US\$ 8 million of debt relief in the recent G-8 summit, losses incurred by the sugar regime will reach US\$ 40 million. ODA flows to LAC have fallen. The SIDS, which are supposed to be given special recognition, have seen flows halved in 2000-2003 compared to the same period in the 1990s. Access to drugs remains riddled with inequalities, and ICT spending at US\$ 400 in LAC remains well below the US\$ 2000-3000 in the developed countries.

8. The Mauritius Declaration, 2005. 
There are clearly successes and failures, but overall LAC is better placed than many other regions in the developing world to reach (or nearly reach) the millennium development goals, though this has its own dangers for two reasons. First, the region has the world's most unequal and concentrated pattern of income distribution. There are persistent pockets of poverty within medium and high-level income countries, and there is a growing inequality between the countries of the region, characteristics of the Caribbean as a subregion as well. The surest way to meet targets within countries would be to target the poorest, but there are clearly important political implications in such a policy. The difficulties facing the Hugo Chavez regime in Venezuela at the moment show some of the problems a policy of this kind would face.

Second, the fact that most countries feature in the medium-level category, or better in the Human Development Index, means they can be conveniently ignored by the international donor community. The Caribbean in particular suffers from being overlooked, being furthermore a region of mainly small states with low visibility and little political clout. Its visibility has serious implications for the region. While most of the millennium development goals embody the commitment of resources at the domestic level, these by themselves will not be enough to achieve the goals. External support is still needed. There is at present little sign that external support is (or will be) forthcoming.

\section{POLITICAL DEVELOPMENT}

The importance of the political dimension in development emerged with the debate on the need for "good governance" in the 1990s. While originally concerned with sub-Saharan Africa, the imperative of good governance has spread throughout the developing world, including the Caribbean. A recent discussion of governance in the region, involving a large number of regional academics and policy makers, opens with the observation that

[d]espite continuing debate on its ideological origins and the persistence of a variety of definitions regarding its specific content, there is increased recognition that the concept of good governance, broadly conceived, is an important requisite for the promotion of an optimal level of development, the guarantee of human rights and freedom, and the maintenance of social and political stability. (Hall \& Benn 2003:x)

Within the Caribbean the practice of good governance for most states has involved two elements: the role of government in delivering development and the fostering of democratic governance to sustain development.

In the last twenty-five years there has been a substantial debate on the role of the state in development. There is still no consensus, although since the publication of the World Bank Development Report on The State in a 
Changing World the state is widely seen as playing a "catalytic, facilitating role, encouraging and complementing the activities of private businesses and individuals" (World Bank 1997:3) within a broadly "neo-liberal" development paradigm. This demands an "effective state." There are two elements to such a state. First, a state's role must match its capabilities, which demands a sharper focus on fundamentals, particularly on core activities that are crucial to development (establishing a foundation of law, macroeconomic stability, basic social services and infrastructure, and protecting the vulnerable and the environment). Second, the state's capability must be raised by reinvigorating its public institutions through a number of measures including designing effective rules and restraints to check arbitrary state actions and corruption, greater competition among state institutions to increase their efficiency, improved performance of state institutions through better pay and incentives, and making the state more responsive to the needs of people through broader participation and decentralization.

There is a distinction to be made here between two categories of state in the Caribbean: those that lack both elements and those who lack only the second. In the first category are Haiti and Guyana, and more marginally (and arguably) the Dominican Republic. The priority here, and particularly for Haiti, is political reforms to improve capacity and accountability. It almost goes without saying that these will be difficult to achieve and will involve long-term commitments, not only from those within the country but also from those outside (including regional agencies) who can promote and facilitate such changes. The priority in the second category is the building of institutions for an efficient, effective, and economical public sector. In the Caribbean the share of government expenditure in GDP has risen from 27 percent of GDP (19901997) to 32 percent GDP (1998-2003), which suggests the test of economy is not being met. Some of this increase is linked to increasing debt costs and to exogenous shocks (including hurricanes). Some also comes from the higher costs of delivering public services in small states (e.g., health and education in outlying islands). However, unless expenditure can be matched by government revenues (which at the moment it is not) then the public sector must do more with less. This puts a premium on programs of public sector reform designed to deliver efficient and effective administration. In the Commonwealth Caribbean such reform programs have been in place in a number of states for a decade or more, with so far mixed results. Only Jamaica shows mostly positive outcomes and a strong and sustained commitment to reform. The difficulties involved show this to be an area that needs further attention.

The record of democratic government (defined as liberal democracy) in the Caribbean is generally very good. Of course, there are exceptions. The twofold distinction identified earlier could also apply to the immediate prospects for democracy. There is a major crisis in Haiti and little apparent will to solve it by the political elites within the country. Guyana is currently stable 
although the country remains polarized by race. The Dominican Republic presents a more hopeful picture although the political process remains highly personalized and factionalized. Cuba remains a unique problem in which the death of Castro and the transition from the rule of the Communist party to a more pluralistic system is long promised but seemingly as distant as ever. In all four, processes of change will need to follow a distinct trajectory tailored to individual circumstance.

Elsewhere the problems of democracy seem to cluster around a number of issues that have been identified in a series of conferences held in the region throughout the 1990 s to the present day. ${ }^{9}$ They include apathy toward, and alienation from, existing political institutions, seen in declining turn-out for elections; increasing social anomie and disregard for social conventions in the breakdown of a culture of civil discourse and the rise of antisocial behavior; and growing corruption and political violence, linked to the growth of drug trafficking. In his book investigating "the Westminster experience in the Caribbean," one of the region's most distinguished political scientists, Selwyn Ryan (1999), points to failing political parties, bureaucracies under stress, and judicial systems in crisis. He also comments on regionwide political practices among the political elite which erode good governance, including authoritarian leadership styles, adversarial politics (political and ethnic tribalism), the cultivation of political patronage, and the encouragement of zero-sum attitudes in government in which "the winner takes all," freezing out the opposition and acting against political consensus.

While these are significant deficiencies they nonetheless have to be balanced against the overall record of high and continuing liberal democratic processes (widely regarded, at least among the major donor countries and international agencies, as the essence of good governance) throughout the Caribbean. In the period 1980-2004, 66 general elections were held in the Commonwealth Caribbean, and everywhere governments have been changed by ballot. More recently, the "political corruption index" shows an improvement regionally from 16 in 1990-1997 to 6 in 1998-2002 (with the worst offender being Suriname at 106 and 43, respectively). And lastly, the Caribbean remains the most democratic region in the developing world (probably because it is mainly made up of small states, independent and dependent, since small states tend to be more democratic than large ones). In short, there is undoubtedly need for better governance, but a sense of proportion must also accompany policy recommendation.

9. See for example Hall \& Benn 2003; Governance and Democratic Development in Latin America and the Caribbean (New York: United Nations Development Programme, 1996) and Organization of American States, Westminster in the Caribbean: Viability Past and Present, Prospects for Reform or Radical Change (Washington, DC, 2002); available at www.upd.oas.org. 
The dominant development policy paradigm in the Caribbean today is neoliberalism. It began with the structural adjustment crises in a number of countries in the 1980s. Before the 1980s two development paradigms held sway (see Payne \& Sutton 2001). The first was the modernization paradigm of the 1950s and 1960s associated with the work of Arthur Lewis, which drew on the experience of "Operation Bootstrap" in Puerto Rico. The essence of the strategy was a program of "industrialization by invitation," which sought to combine the labor surplus in the region with modern (largely foreign) capital to create industries to serve the regional and foreign markets. The state was to play an important role in developing infrastructure and providing fiscal incentives. It also promoted regionalism through the creation of regional trade mechanisms to offset the disadvantage of small size. Tourism was also encouraged (particularly following the Cuban Revolution, which "diverted" tourists to other Caribbean islands).

In some ways the policy was successful. The rates of growth in the 1950s and 1960s were around 5 percent (higher than any period since that time). But there was disappointment in two areas: unemployment and underemployment remained high, and the region was still dependent on the outside world for its development dynamic. These disappointments were turned into critiques within the University of the West Indies, resulting in a new paradigm of development associated with "plantation economy" (similar in many ways to the thinking of the Latin American "dependency" theorists) pioneered by Lloyd Best and popularized by George Beckford. This paradigm of development attributed underdevelopment to the historical and continuing legacy of the plantation and argued for a pattern of development that was regionally more specific and political in its aims. In this it was influenced both by the example of the Cuban Revolution and by the achievement of independence in a number of countries in the Commonwealth Caribbean, which nominally gave the state greater powers to advance development. Under the influence of independence the state took a more commanding role in the economy and regional integration was strongly promoted alongside an espousal in the international system of various Third World causes throughout the 1970s.

The debt crisis, U.S. policy under Ronald Reagan, and structural adjustment dealt a mortal blow to this paradigm. The politicos were replaced by the tecnicos. The discussions about development were no longer ones of grand design developed within the region for the region but about how best to administer the programs that were designed elsewhere under the neoliberal paradigm as expressed in the "Washington Consensus." The 1990s onward witnessed the further entrenchment of this paradigm within the region as it sought the best way to accommodate to and benefit from globalization. 
It has two elements. The first is predicated on closer integration with the global economy through developing greater competitiveness in some products and niche markets in others. It builds on studies undertaken in the various international and regional organizations and finds a particular expression through the concept of "strategic global repositioning" (SGR) advocated by Richard Bernal, the current director of the Caribbean Regional Negotiating Machinery. He defines it as

\begin{abstract}
a process of repositioning a country in the global economy and world affairs by implementing a strategic medium to long term plan formulated from continuous dialogue of the public sector, private sector, academic community and the social sector. It involves proactive structural and institutional transformation (not adjustment) focussed on improvement and diversification of exports and international economic and political relations. Achieving SGR requires changes in both internal and external relations. The external relations are of paramount importance because of the highly open and vulnerable nature of these small, developing economies. (Bernal 2000:311)
\end{abstract}

The concept of SGR has found favor within the region and without. For example, it was commended in major meetings in the World Bank in both 2000 and 2005 as a strategy particularly suited to small states. ${ }^{10}$

The other is closer Caribbean integration. In 1989 the heads of government of CARICOM made a decision to reinvigorate the integration process (originally launched in 1968) through the creation of the CARICOM Single Market and Economy (CSME). This was to include a fully functioning common market, the harmonization of macroeconomic policies and eventually monetary integration. In 1994 regional leaders established the Association of Caribbean States (ACS) to encourage closer cooperation throughout the region and the proximate Latin American mainland. Neither has fulfilled its promise. The ACS has proved ineffectual. CARICOM has fared a little better. Following long delays, some key elements of the single market (free movement of goods and services) were established as of January 2006 between Barbados, Belize, Guyana, Jamaica, Suriname, and Trinidad and Tobago. There is also some limited free movement of labor. But the smaller countries of the Organisation of Eastern Caribbean States remain concerned about its effect on them, and the Bahamas has recently decided not to join. Little has been done to establish the single economy. The slow pace of change has led some to question whether the CSME is really that important to the region. It remains of significance for most political leaders and for the tecnicos, but fails to excite the public because of its "top-down" approach to integration. It also suffers, according to Norman

10. Lino Briguglio, Bishnodat Persaud \& Richard Stern, Toward an Outward-Oriented Development Strategy for Small States: Issues, Opportunities, and Resilience Building (Commonwealth Secretariat and World Bank, 2005); available at www.worldbank.org. 
Girvan (former secretary general of the ACS), from serious defects in the original design, which retains too much national sovereignty for implementation. The completion of the CSME, he argues, requires agreement on the selective pooling of national sovereignty in defined areas - a policy most Caribbean leaders are at present unwilling to discuss, let alone implement. ${ }^{11}$

The current development strategy, compared to the 1970s and even the modernization vision of the $1950 \mathrm{~s}$ and $1960 \mathrm{~s}$, is one where the specific regional dimension is missing. It is largely derivative, and "regional input" (e.g., Bernal 2000) has been limited. The dangers this approach of overlooking regional specificity can carry can be demonstrated using the two reports cited in my opening remarks. The World Bank report is a massive document providing a wealth of empirical evidence but presenting it very much within the approved (now post-Washington Consensus) thinking that permeates the bank. This type of thinking is very evident if one turns to the bibliography and the various studies that accompany the report. In them there is little use made of local consultants or national or regional studies. It is tempting to conclude that its authors in the bank are secure in their "paradigm" and that the World Bank has imposed a "one-size-fits-all" model on the region.

A similar critical view is held by the region's leading development economist. In a presentation to the World Bank in June 2005, Clive Thomas argued that its report $A$ Time to Choose "betrays a failure by its authors to pay proper and respectful regard to the institutional memory of the region's discourses on economic matters," 12 thereby highlighting the failure of the bank to fully appreciate the debate on development policy in earlier years. He also criticizes its methodology on these grounds, arguing that the report pays

\begin{abstract}
insufficient attention to the historical and institutional context of the region and the microanalysis of firms. My proposition is that when these are sufficiently embedded in the analysis, it might well suggest different lines of departure, different emphases, and perhaps a different perspective from which to frame the development problematique in the region from that the report adopts. ${ }^{13}$
\end{abstract}

In short, the report is not comprehensive enough in its vision nor mindful enough of the specific realities of the Caribbean region.

11. Norman Girvan, "The CARICOM Single Market and Economy: Challenges to Its Completion" (presentation to the Caribbean Study Group of the Royal Institute of International Affairs, London, March, 2006).

12. C.Y. Thomas, "The World Bank's A Time to Choose: Comment" (remarks to the Caribbean Forum for Development, sponsored by the Caribbean Development Bank, Barbados, June, 2005).

13. Thomas, "Comment" 2005. 
The ECLAC study tries to provide an alternative view. It takes to task the "one-size-fits-all" approach and argues that "gradual and partial reforms aligned with actual conditions in each country and with existing institutional structures have yielded better results than reforms that were not filtered through the sieve of practice, experience and internal discussion" (my emphasis). It also argues in respect of achievement of the millennium development goals that: "economic growth is a necessary but not sufficient condition for the reduction of poverty and inequality. The workings of the market must be given greater scope while at the same time improving the role of the state." In short, it provides an endorsement of the mixed economy and argues for an approach sensitive to local realities.

I find the ECLAC approach preferable. But I would go further. At the very beginning I noted the exclusion of Cuba and Haiti from this article on the grounds that they were "atypical" Caribbean states. But what is a "typical" Caribbean state? Many years ago the celebrated anthropologist Sidney Mintz (1971) provided the answer in his depiction of the region as a "sociocultural area" defined by multiple historical, economic, social, political, and cultural criteria. Within this framework Cuba and Haiti would occupy the central place. They would, in fact, be the "typical" Caribbean state. In thinking again about development in the region the approach taken by Mintz should very much be kept in mind. Development policy demands a strong element of "regional specificity" if it is to be credible and is to work. Globalization may be linking countries and territories to different parts of the world like separate spokes in a wheel, but to extend the analogy, every wheel has a hub that gives it shape and strength. The Caribbean region is a hub and development policy must build from the center outward if it is to deliver the right kind of development - which is also sustainable development - to its people.

It follows that development must be culturally aware and environmentally sensitive. In the Caribbean there are moves to get the Caribbean Sea declared as a special area with special protection. In the world at large the Caribbean is probably better known for its music than for any other product. There must be a way in which such vital elements can be combined with economic, social, and political criteria to bring about a development policy in the Caribbean that is truly multidimensional and practically beneficial for all its peoples. In such an exercise there should be full engagement with all the region's peoples and a frank appraisal of what has and has not worked in the past. This must encompass Cuba (and Haiti) as well. There are plenty of lessons that can be drawn from a rich historical past. These need to be recovered and integrated within the development discourse in the region to provide the roots for a "grounded account" of development against which more fashionable propositions can be tested, and if acceptable, grafted on to experience to promote new and vigorous growth. 


\section{REFERENCES}

BERnAL, R., 2000. The Caribbean in the International System: Outlook for the First Twenty Years of the $21^{\text {st }}$ Century. In Kenneth O. Hall \& Denis Benn (eds.), Contending with Destiny: The Caribbean in the $21^{\text {st }}$ Century. Kingston: Ian Randle, pp. 295-325.

HaLl, KenNeTH O. \& DeNis BenN, 2003. Introduction. In Kenneth O. Hall \& Denis Benn (eds.), Governance in the Age of Globalisation: Caribbean Perspectives. Kingston: Ian Randle, pp. X-xxv.

MINTZ, SIDNEY, 1971. The Caribbean as a Socio-cultural Area. In Michael M. Horowitz (ed.), Peoples and Cultures of the Caribbean: An Anthropological Reader. Garden City NY: Natural History Press, pp. 17-46.

Payne, Anthony \& Paul Sutton, 2001. Charting Caribbean Development. Basingstoke U.K.: Warwick University Caribbean Studies/Macmillan Education.

RYAN, SELWYN, 1999. Winner Takes All: The Westminster Experience in the Caribbean. St. Augustine, Trinidad: ISER, University of the West Indies.

SANDERS, RONALD, 2002. The Fight against Fiscal Colonialism. Round Table: The Commonwealth Journal of International Affairs 365:325-48.

WOODWARD, R., 2004. The OECD's Harmful Tax Competition Initiative and Offshore Financial Centres in the Caribbean Basin. In Ramesh Ramsaran (ed.), The Fiscal Experience in the Caribbean: Emerging Issues and Problems. St. Augustine, Trinidad: Caribbean Centre for Monetary Studies, University of the West Indies, pp. 604-44.

WORLD BANK, 1997. World Development Report 1997: The State in a Changing World. Oxford: Oxford University Press.

\section{PAUL SUTTON}

Department of Politics and International Studies

University of Hull

Hull, HU6 7RX

United Kingdom

$<$ P.K.Sutton@hull.ac.uk.> 